\title{
PERANCANGAN APLIKASI EDUKASI PAKAIAN ADAT TRADISIONAL INDONESIA BERBASIS ANDROID
}

\author{
Makiyah Inaya ${ }^{1}$, Dona Katarina ${ }^{2}$, Siti Julaeha ${ }^{3}$ \\ Informatika $^{1}$, Informatika ${ }^{2}$, Informatika ${ }^{3}$ \\ Fakultas Teknik dan Ilmu Komputer, Fakultas Teknik dan Ilmu Komputer², \\ Fakultas Teknik dan Ilmu Komputer ${ }^{3}$ \\ Universitas Indraprasta $\mathrm{PGRI}^{1}$, Universitas Indraprasta $\mathrm{PGRI}^{2}$, Universitas \\ Indraprasta $\mathrm{PGRI}^{3}$ \\ Makiyainayah010@gmail.com ${ }^{1}$,donakatrin1503@gmail.com², \\ nyooi.sholeha@gmail.com ${ }^{3}$
}

\begin{abstract}
Abstrak: Pakaian adat merupakan pakaian tradisional yang masih ada saat ini dan melambangkan kebudayaan atau ciri khas masyarakat setempat, pakaian adat memiliki kekurangan berupa terbatasnya tampilan pakaian adat secara visual sehingga berkurangnya daya tarik masyarakat khususnya peserta didik. Metode penelitian yang dilakukan adalah grounded research yaitu suatu metode penelitian yang mendasarkan diri kepada fakta dan menggunakan Analisa perbandingan yang bertujuan untuk mendapatkan konsep-konsep, membuktikan teori dan mengembangkan teori dimana pengumpulan data dan Analisa data berjalan pada waktu yang bersamaan. Tujuan penelitian ini adalah untuk merancang aplikasi edukasi pakaian adat tradisional indonesia berbasis android yang dilengkapi dengan kuis untuk menjadi sebuah wadah atau tempat untuk berbagi pengetahuan mengenai kebudayaan di Indonesia yang dikemas secara menarik sehingga dapat memunculkan daya tarik bagi masyarakat indonesia khususnya peserta didik sekolah dasar. Hasil penelitian ini menghasilkan aplikasi edukasi pakaian adat tradisional Indonesia berbasis android.
\end{abstract}

Kata kunci: Aplikasi, Edukasi, Pakaian Adat, Tradisional, Indonesia

\begin{abstract}
Traditional clothing is traditional clothing that still exists today and symbolizes the culture or characteristics of the local community, traditional clothing has disadvantages in the form of limited visual appearance of traditional clothing so that it reduces the attractiveness of the community, especially students. The research method used is grounded research, which is a research method that is based on facts and uses comparative analysis which aims to obtain concepts, prove theories and develop theories where data collection and data analysis are carried out at the same time. The purpose of this research is to design an educational application for traditional Indonesian traditional clothing based on android which is equipped with a quiz to become a place or place to share knowledge about culture in Indonesia which is packaged attractively so that it can create an attraction for Indonesian society, especially elementary school students. The results of this study produce an educational application for traditional Indonesian traditional clothing based on android.
\end{abstract}

Keywords: Application, Education, Traditional Custom, Traditional, Indonesia

\section{PENDAHULUAN}

Di era modern saat ini banyak kalangan masyarakat khususnya peserta didik sekolah dasar yang belum mengetahui mengenai pakaian adat tradisional yang ada di Indonesia, karena banyak dan beragam bentuknya, seolah-olah kita tidak peduli dengan kekayaan pakaian adat tradisional Indonesia. Banyak sekali situs-situs di internet dan buku-buku yang membahas mengenai keanekaragaman budaya yang ada di Indonesia. Sebagai

Ciptaan disebarluaskan di bawah Lisensi Creative Commons Atribusi 4.0 Internasional. 
salah satu contoh, keanekaragaman budaya Indonesia dapat dipelajari dengan mudah melalui buku Rangkuman Pengetahuan Umum Lengkap atau RPUL sekolah dasar yang banyak dimiliki oleh peserta didik sekolah dasar.

Tetapi, untuk mempelajari begitu banyak keanekaragaman budaya yang ada di Indonesia hanya dari buku RPUL saja dirasa kurang diminati oleh masyarakat dikarenakan beberapa faktor yang salah satunya yaitu daya tarik masyarakat khususnya peserta didik sekolah dasar. Oleh karena itu, dengan adanya sebuah aplikasi yang akan menampilkan informasi mengenai pakaian adat tradisional yang ada pada setiap provinsi di Indonesia bertujuan agar dapat membantu masyarakat khususnya peserta didik sekolah dasar dalam mendapatkan pengenalan dan pengetahuan mengenai berbagai macam keanekaragaman pakaian adat tradisional yang ada di Indonesia.

Dengan permasalahan yang diuraikan diatas, maka dalam rangka menjaga atau melestarikan budaya yang ada di Indonesia, perlu sebuah wadah atau tempat untuk berbagi pengetahuan mengenai kebudayaan di Indonesia yang dikemas semenarik mungkin agar memunculkan daya tarik, maka diperlukan sebuah aplikasi edukasi pakaian adat tradisional indonesia berbasis Android

\section{METODE DAN MATERI}

Penelitian yang berhubungan dengan pengenalan seni budaya tradisional indonesia sudah pernah dilakukan oleh beberapa peneliti yaitu diantaranya Rendika Ramadhan (2018) dalam penelitiannya ini berisi tentang pengenalan seni budaya di pulau jawa yang dibuat agar dapat menarik minat anak-anak maupun orang dewasa untuk mengenal dan memperluas wawasan tentang seni budaya di pulau jawa. Metode yang digunakan oleh Rendika Ramadhan untuk merancang aplikasi ini adalah metode waterfall.

Penelitian yang dilakukan oleh Rendika Ramadhan menggunakan metode waterfall membuat pengembangan sistem yang dibuat menjadi lebih efektif karena tahap demi tahap yang dilalui harus menunggu selesainya tahap sebelumnya dan berjalan berurutan (Rendika Ramadhan, 2018).

Menurut (Pressman, 2015:42) model waterfall adalah model klasik yang bersifat sistematis, berurutan dalam membangun software. Nama model ini sebenarnya adalah "Linear Sequential Model". Model ini sering disebut juga dengan "classic life cycle" atau metode waterfall. Model ini termasuk ke dalam model generic pada rekayasa perangkat lunak dan pertama kali diperkenalkan oleh Winston Royce sekitar tahun 1970 sehingga sering dianggap kuno, tetapi merupakan model yang paling banyak dipakai dalam Software Engineering (SE). Model ini melakukan pendekatan secara sistematis dan berurutan. Disebut dengan waterfall karena tahap demi tahap yang dilalui harus menunggu selesainya tahap sebelumnya dan berjalan berurutan.

Metode penelitian yang dilakukan adalah grounded research yaitu suatu metode penelitian yang mendasarkan diri kepada fakta dan menggunakan Analisa perbandingan yang bertujuan untuk mendapatkan konsep-konsep, membuktikan teori dan mengembangkan teori dimana pengumpulan data dan Analisa data berjalan pada waktu yang bersamaan. Teknik pengumpulan data yang digunakan oleh peneliti dalam melakukan pengumpulan data adalah sebagai berikut :

2.1. Studi Pustaka (Library Research)

Studi Pustaka (Library research) merupakan cara untuk mencari referensi dari penelitian terkait. Penelitian dilakukan dengan mengumpulkan bahan-bahan pustaka. Beberapa jurnal terkait penelitian telah dimasukan sebagai bahan acuan dalam membuat aplikasi pada penelitian kali ini. Peneliti melakukan studi literatur dengan mengumpulkan data dari penelitian terdahulu, pembelajaran dari beberapa literatur dan dokumen seperti buku, jurnal dan teori-teori lainnya yang mendukung penelitian terkait konsep aplikasi edukasi rumah adat tradisional Indonesia pada perangkat bergerak berbasis Android.

2.2. Studi Lapangan (Field Research)

Studi Lapangan (Field Research) merupakan penelitian yang dilakukan dengan cara melakukan pengamatan langsung pada obyek yang diteliti untuk memperoleh data primer. Adapun Teknik pengumpulan data yang dilakukan adalah sebagai berikut:

\subsubsection{Observasi}

Observasi adalah suatu metode pengumpulan data yang digunakan dengan mengadakan pengamatan yang disertai dengan pencatatan-pencatatan terhadap keadaan atau perilaku objek sasaran yang dilakukan secara langsung pada lokasi yang menjadi objek penelitian.

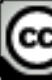




\subsubsection{Wawancara}

Menurut (Sugiyono, 2013:24) Wawancara merupakan pertemuan dua orang untuk bertukar informasi dan ide melalui tanya jawab, sehingga dapat dikonstruksikan makna dalam suatu topik tertentu. Dalam hal ini yang diwawancarai peneliti adalah salah satu pengurus anjungan daerah taman mini Indonesia indah.

\subsubsection{Dokumentasi}

Metode documenter atau dokumentasi merupakan cara untuk mengumpulkan data dengan cara mengutip dan mencatat data yang terdapat dalam dokumen-dokumen yang ada relevansinya dengan masalah yang akan diteliti yang terdapat dilapangan seperti buku-buku perpustakaan, arsip, dan media elektronik berupa internet.

Metode dokumentasi ini digunakan untuk mendapatkan data berkenaan dengan penelitian tentang sejarah dan informasi mengenai rumah adat yang terdapat di anjungan daerah taman mini indonesia indah, antara lain diperoleh dari wawancara dan observasi yang kemduian didokumentasikan dalam bentuk tulisan dan beberapa dokumen foto-foto yang berkaitian dengan penelitian ini. Data dokumentasi ini diperoleh dari anjungan daerah taman mini indonesia indah, internet, dan buku-buku yang relevan berkenaan dengan informasi mengenai rumah adat tradisional indonesia.

\section{PEMBAHASAN DAN HASIL}

Hasil dan pembahasan dari pembuatan aplikasi edukasi pakaian adat tradisional Indonesia adalah sebagai berikut:

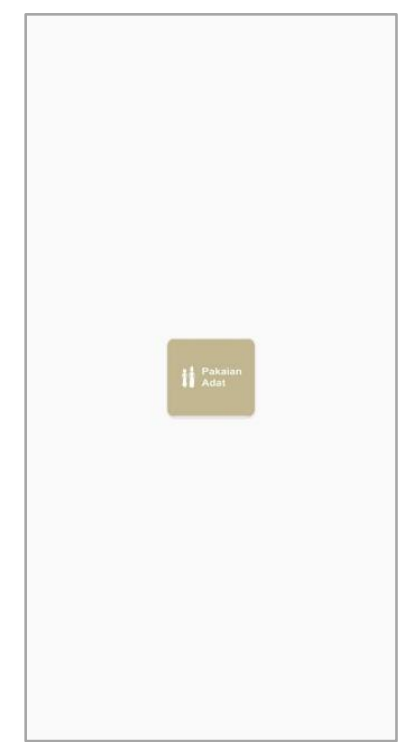

Gambar 1. Tampilan Splashscreen

Tampilan awal yang pertama kali muncul saat aplikasi dibuka oleh pengguna sebelum masuk ke halaman utama atau beranda. Splashscreen digunakan untuk menampilkan logo dan mempunyai kisaran waktu sekitar 5 detik kemudian setelah waktu yang ditentukan selesai maka akan masuk ke menu utama. 


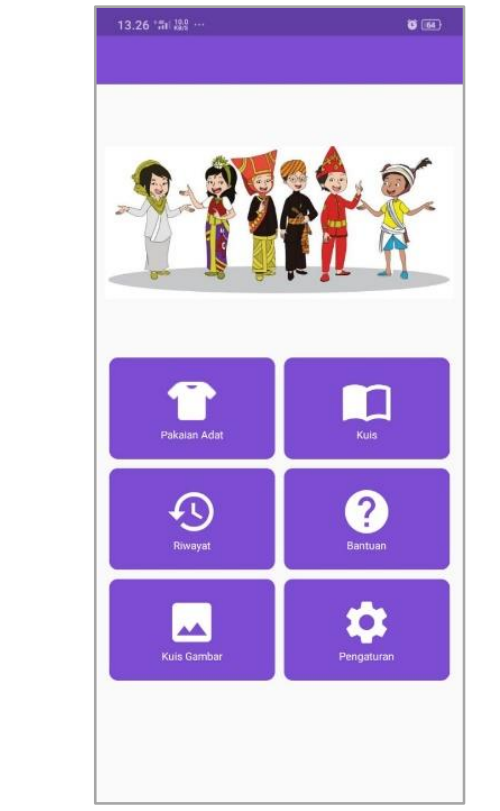

Gambar 2. Tampilan Menu Utama

Pada menu utama disini ditampilkan enam menu yaitu menu pakaian adat, menu kuis, menu riwayat, menu bantuan, menu kuis gambar, menu pengaturan.

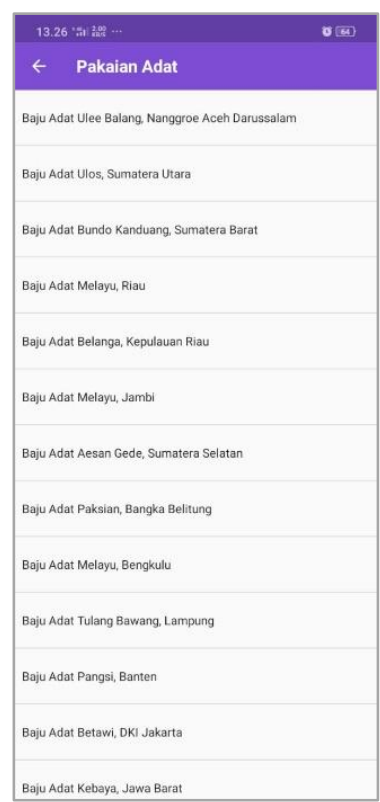

Gambar 3. Tampilan Menu Pakaian Adat

Tampilan menu pakaian adat ini berisi daftar nama-nama pakaian adat, pada tampilan disini pengguna dapat melihat penjelasan dari pakaian adat itu sendiri. 


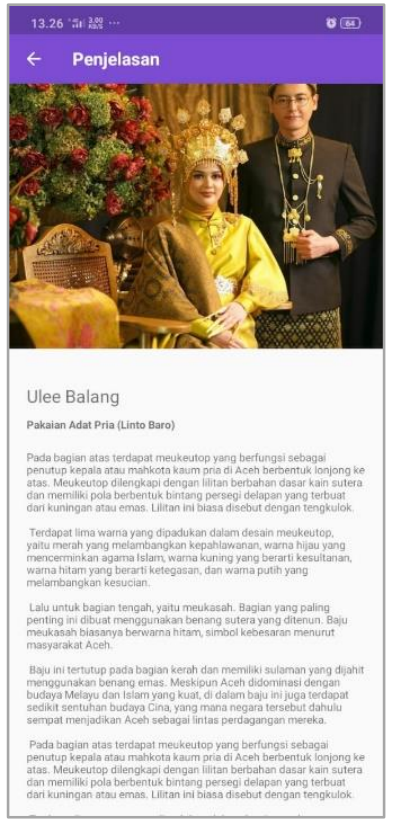

Gambar 4. Tampilan Penjelasan Pakaian Adat

Pada tampilan ini terdapat penjelasan pakaian adat.

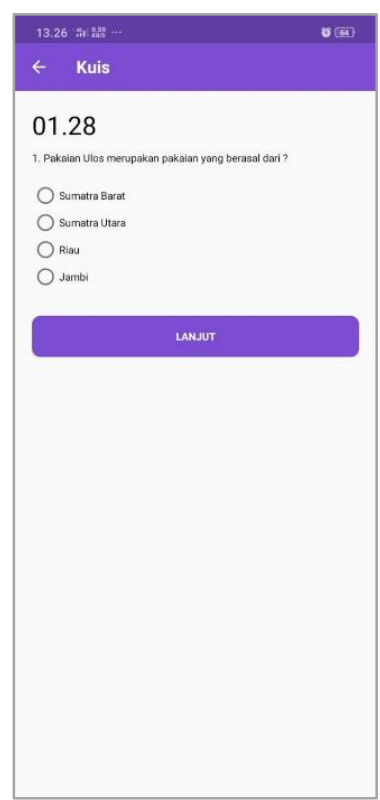

Gambar 5. Tampilan kuis

Pada tampilan kuis ini, akan ditampilkan 10 pertanyaan secara acak dengan waktu 90 detik. Dimana 1 pertanyaan itu bernilai 10 skor. Apabila waktu sudah habis dan pengguna belum selesai menjawab 10 pertanyaan tersebut, maka aplikasi akan menampilkan doalog untuk melajutkan kuis, apabila ingin dilanjutkan makan akan membuka soal baru jika tidak dilanjutkan maka kuis dianggap selesai. 


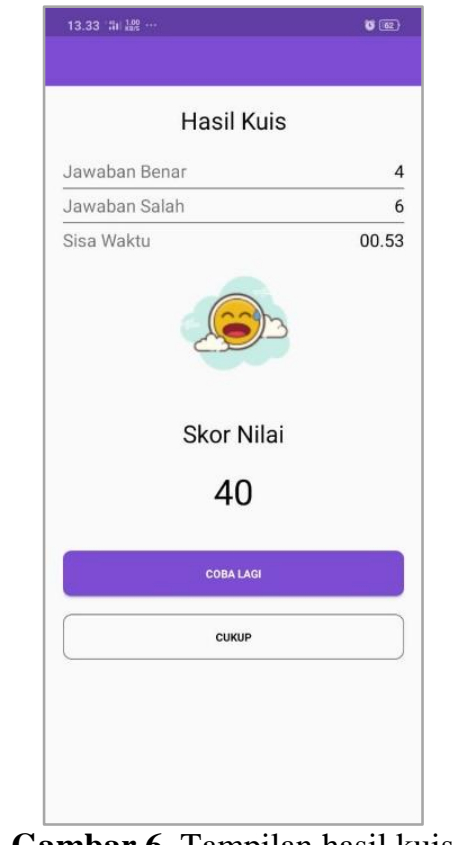

Pada tampilan hasil kuis ini, akan ditampilkan hasil skor dari pertanyaan-pertanyaan yang telah dijawab pengguna. Pada tampilan skor disini menampilkan jumlah soal benar, salah dan sisa waktu dan memiliki dua tombol yaitu untuk mencoba lagi dan cukup.

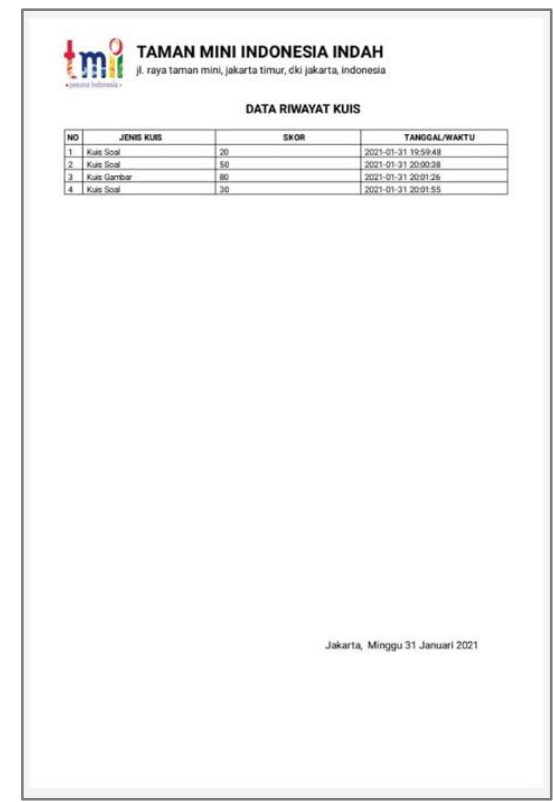

Gambar 7. Tampilan Layar Laporan Riwayat

Tampilan ini merupakan contoh data laporan riwayat yang berbentuk format PDF, untuk melakukan penyimpanan laporan PDF yaitu tekan menu pada pojok kanan atas kemudian pilih simpan. 


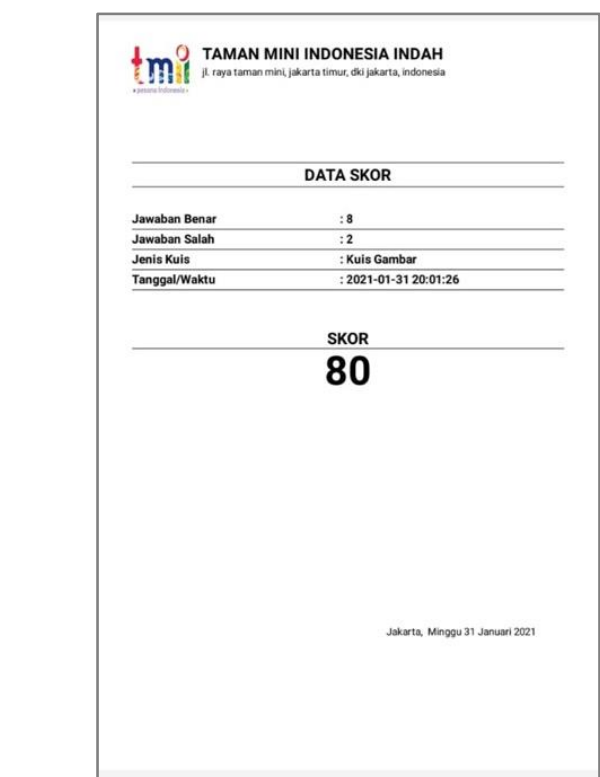

Gambar 8. Tampilan Layar Laporan Detail Riwayat

Tampilan ini merupakan contoh data laporan detail riwayat yang berbentuk format PDF, untuk melakukan penyimpanan laporan PDF yaitu tekan menu pada pojok kanan atas kemudian pilih simpan.

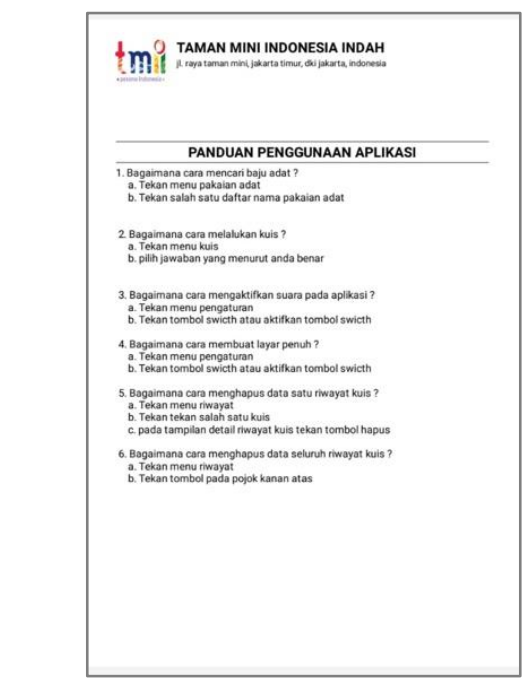

Gambar 9. Tampilan Layar Laporan Bantuan

Tampilan ini merupakan contoh data laporan Bantuan yang berbentuk format PDF, untuk melakukan penyimpanan laporan PDF yaitu tekan menu pada pojok kanan atas kemudian pilih simpan. 


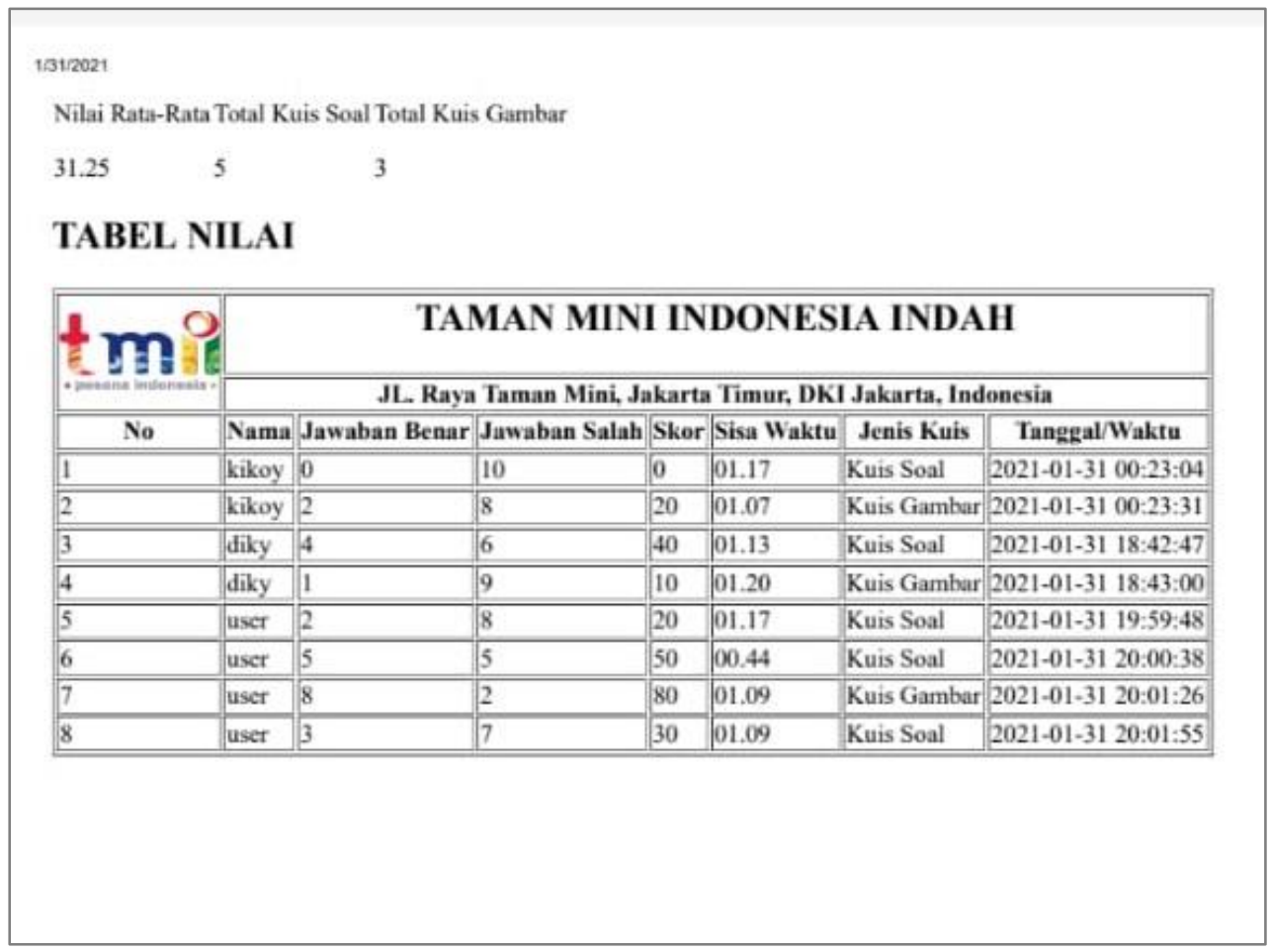

Gambar 10. Tampilan Layar Laporan Data Skor Nilai Rata-Rata

Tampilan ini merupakan contoh data laporan data skor nilai rata-rata yang berbentuk format PDF, untuk melakukan penyimpanan lapran PDF yaitu tekan menu pada pojok kanan atas kemudian pilih simpan.

\section{KESIMPULAN}

Berdasarkan hasil analisis dan pembuatan aplikasi edukasi pakaian adat tradisional Indonesia ini, maka peneliti dapat menarik kesimpulan yaitu aplikasi edukasi pakaian adat tradisional Indonesia ini dapat membantu pengguna dalam mendapatkan informasi tentang pakaian adat Indonesia dengan lebih menarik dan aplikasi ini dilengkapi dengan kuis yang menambah daya tarik pengguna khususnya peserta didik sekolah dasar.

\section{REFERENSI}

[1] Arifianto, Teguh. (2011). Membuat Interface Aplikasi Android Lebih Keren dengan LWUIT. Yogyakarta: Andi Publisher.

[2] Gelinas, J.U., Dull, Richard, B., \& Wheeler, Patrick R. (2012). Accounting Information Systems. South Western: Cengage Learning.

[3] Kristanto, Andi. (2018). Perancangan Sistem Informasi dan Aplikasinya. Yogyakarta: Gava Media.

[4] Pressman, R. (2015). Rekayasa Perangkat Lunak: Pendekatan Praktisi Buku 1. Yogyakarta: Andi.

[5] Recruitment. (2019). Perkembangan Android Sistem dari Astro hingga Pie. https://toghr.com/perkembanganandroid-sistem/. (2/5/2020)

[6] Rizky, Soetam. (2011). Konsep Dasar Rekayasa Perangkat Lunak. Jakarta: Prestasi Pustaka.

[7] Romney, Marshal. B. \& Steinbart, P. J. (2015). Sistem Informasi Akuntansi. Jakarta: Salemba Empat.

[8] Safaat, Nazruddin h. (2012). Pemrograman Aplikasi Mobile Smartphone dan Tablet PC berbasis android. Bandung: Informatika Bandung.

[9] Subhan, Mohamad. (2012). Analisa Perancangan Sistem. Jakarta: Lentera Ilmu Cendikia.

[10] Sugiar, Yogi. (2014). Komputer Si Mesin Pintar. Bandung: Oasebuku.

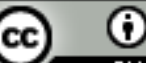

Ciptaan disebarluaskan di bawah Lisensi Creative Commons Atribusi 4.0 Internasional. 
Journal of Information System, Applied, Management, Accounting and Research. http://journal.stmikjayakarta.ac.id/index.php/jisamar, jisamar@stmikjayakarta.ac.id, jisamar2017@gmail.com e-ISSN: 2598-8719 (Online), p-ISSN: 2598-800 ( Printed), Vol. 5 No.1 Februari 2021

[11] Sugiyono. (2011). Metode Penelitian Kuantitatif Kualitatif dan R\&D. Bandung: Alfabeta.

[12] Susanto, Azhar. (2013). Sistem Informasi Akuntansi. Bandung: Lingga Jaya.

[13] Sutabri, Tata. (2012). Analisis Sistem Informasi. Andi: Yogyakarta.

[14] Syah, Muhibbin. (2010). Psikologi Pendidikan. Bandung: Remaja Rosdakarya Offset.

[15] Yakub. (2012). Pengantar Sistem informasi. Yogyakarta: Graha Ilmu.

[16] Kurniawan, Hendra, Eri Mardiani dan Nur Rahmansyah. 2011. Aplikasi Penjualan dengan Program Java Netbeans, Xampp, dan iReport. Jakarta: PT Elex Media Komputindo 